\title{
Seven Doctoral Theses in Demography ${ }^{1}$
}

\author{
JARL LINDGREN
}

Within one year seven doctoral theses in demography have been accomplished in Finland.

Four of the theses were written at the Department of Sociology at the University of Helsinki where demography is an alternative subject for sociology with its own chair. In addition to these theses, one student from the Department of Sociology took his doctor's degree in London. According to the British practice, his work has not been published as a separate thesis, but parts of it have been included in several scientific publications.

The chair in demography at the University of Helsinki was established in 1974. Gradually, the number of students majoring in demography has grown. Simultaneously, students from other fields, such as medicine, history and social policy, who want to use demographic aspects in their work have gathered together round the chair with its newly founded Population Research Unit. The professor's chair is held by Tapani Valkonen who, during his professorship together with his research group, has contributed more than any other person to mapping mortality in Finland.

Four of the doctoral theses deal with mortality, but using different approaches. One deals with differences in mortality in older ages related to several factors such as sex, place of residence, socioeconomic and marital status. Another uses a medical aspect. Its aim is to explain why mortality from heart disease is much higher in Eastern Finland than in the western part of the country. The third one concerns mortality differentials among middle-aged women. Here the author examines how different measures of socioeconomic status are related to mortality. In the fourth, the impact of mortality on Finland's last demographically significant subsistence crisis, the great famine of the 1860 s, is examined.

One of the three other dissertations deals with family formation in Estonia related to the sociodemographic background. Special interest is focused on ethnic differences. In another thesis social and societal determinants of disability pensions are examined, using a social policy or properly speaking a pension policy aspect. The last of the seven theses concerns the interaction between household and several societal and demographic factors in a coastal region of Finland from the end of the 1600 s to the 1800 s. It uses a family history approach and is partly based on family reconstruction.

\footnotetext{
'Bibliographic details of the theses are at the end of the article.
} 


\section{The theses}

\section{Origin of regional differences in mortality from heart disease}

The aim of Seppo Koskinen's study, »Origins of Regional Differences in Mortality from Ischaemic Heart Disease in Finland», is to evaluate the role of the various suspected causal factors in the pattern of the Finnish geographical differences in ischaemic heart disease (in the following abbreviated to IHD). This assessment was based upon two sources of information: first, earlier literature about the nature of regional mortality differentials and their possible causes and, secondly, results from empirical analysis of a large mortality data set.

Mortality from IHD is considerably higher in the eastern parts of Finland than in the western coastal areas. In the middle-aged population the eastern mortality excess is approximately 50 percent. This general pattern has prevailed as long as reliable data has been available, that is, for at least half a century. Numerous hypotheses have been forwarded, but very little is actually known about the causal background of this eastwest difference. A review of the earlier literature and the empirical analyses resulted in the following five main descriptive findings.

1) Variations in the current sociodemographic structure of the regional populations did not seem to play a noticeable role in explaining the regional mortality variation in ischaemic heart disease.

2) Regional differences in mortality from IHD have been permanent from the early 1970 s onwards, and apparently also for a much longer time, during the periods of increase as well as decrease in the national mortality rates.

3) Geographic variation in mortality is determined mainly by the region of birth and much less by the region of residence.

4) Regional differences in mortality from IHD is fairly specific to this cause of death.

5) The pattern of regional mortality differences is almost identical to different socioeconomic subgroups of the population.

The results, together with findings from other studies, were employed in evaluating the importance of possible reasons for regional mortality variation. The suspected causal factors were classified into six clusters of factors, which can be postulated to create regional differences in the biological characteristics of people and, consequently, differences in the probability of death from IHD. These are determination of the cause of death, health services, behavioral patterns, social and natural environment and genetic factors. The first two items, cause of death determination and health services, do not play any role in creating mortality variation by region of birth.

Behavioral patterns seem to be largely responsible from that part of eastern excess mortality which is related to living in the east. On the other hand, current behavioral factors probably do not explain the main part of the eastern mortality excess, related to being born in the east. The author states that significant differences in the food culture have traditionally prevailed between the eastern and western parts of the country. Due to some cultural factors, smoking has been more acceptable behavior among eastern than among western men. During the eighties, these behavioral differences seem to have disappeared, perhaps due to the increasing spread of similar cultural influences around the country, including health education, which has advised people to stop smoking and to adopt healthier dietary habits.

Natural environment does not gain support in this analysis as the main reason for mortality differences.

The author concludes that at least three possible explanations seem to remain for the high IHD mortality of women and men born in the east. 
First, the relevant etiological factor may be a genetic characteristic, or combination of such characteristics, particularly prevalent in the eastern population. There are indications of a genetic difference between the eastern and western populations, but we have no strong candidates for the possible quality in question.

Second, the main cause of the mortality contrast may also be an unknown behavioral or environmental factor which already in childhood or youth exerts its more or less irreversible effect on the adult risk of ischaemic heart disease.

Third, the eastern excess mortality could also be caused by some behavioral pattern, relevant in the etiology of IHD, which is adopted rather permanently already during childhood or youth in the eastern cultural milieu.

The stability and consistency of the east-west mortality differential in various subgroups is interpreted to give slightly stronger support to the genetic hypothesis than to the other two hypotheses. Whatever the actual causal factor is, its effect is postulated to be mediated largely via mechanisms other than elevated blood pressure and serum cholesterol.

The smaller fraction of the eastern excess mortality, that associated with residing in the east, is considered to be largely explained by differences in dietary practices and smoking. The author establishes that the dietary and smoking habits in the eastern population have recently become similar to or even more favorable than those in the west. A moderate decline in the eastern excess mortality is therefore expected in the near future.

If mortality differences between regions of birth are mainly due to poor childhood environment, the author assumes that the rapid development of the standard of living since the early decades of this century, particularly in the previously poorest regions, will bring about a marked reduction in the relative mortality differences between regions. If, on the other hand, the high IHD rates among women and men born in the east result mainly from genetic factors, regional mortality differences may well remain close to the present level, until further research possibly discloses the genetic characteristics in question and provides means to reduce their effect. As long as the causes of the excess mortality among persons born in East Finland remain obscure, a reasonable aim for health policy is to achieve further reductions in the level of known risk factors, particularly in those sections of the population which have the highest rates of disease and death.

The data set of the present study was constructed from three subsets which together cover all deaths $(172,000)$ in the age group 35-64 in Finland during the fifteenyear period of 1971-1985. The first subset includes individual death records for the period 1971-1975, linked with individual records of the 1970 Census. The consecutive analogous set was based on linkage of the 1976-1980 death records with the 1975 Census and the last subset covers the deaths in 1981-1985 linked with the 1980 Census records.

Nine census variables, included in each of the censuses, were selected to be analyzed in this study: region of birth, region of residence, level of urbanization, language group, level of education, occupational class and marital status, in addition to age and gender. The analysis was based on a multivariate table for which the data were crosstabulated according to all variables included in the study. The table was analyzed employing a log-linear regression analysis of the mortality rates.

\section{Mortality differentials at older ages}

Tuija Martelin describes in her study, "Differential Mortality at Older Ages», the development of mortality differentials among the elderly during the two past decades, 
particularly according to socioeconomic status. In addition to descriptive information, she discusses hypotheses concerning factors that affect mortality in older ages and the likelihood of further declines in elderly mortality in Finland.

The study showed that remarkable mortality differentials can be found among the elderly. The differences were analogous to but smaller than those found earlier among the middle-aged population. Even at ages 85 years and over, the elderly people with only a basic education, manual workers, as well as those with a small income or poor housing conditions, showed a higher mortality than the more advantaged elderly. Mortality was lower among the married elderly than among the unmarried, and among the Swedish-speaking minority compared to the Finnish-speaking majority. Moreover, living in eastern or northern Finland was associated with a higher mortality compared to the average level.

During 1971-1990, mortality among the elderly declined in each sociodemographic subgroup. In general, differentials did not diminish during the twenty-year period. A particularly alarming observation was that, at least among men, socioeconomic differentials tended to grow. This trend, which has been observed in other studies clearly among middle-aged men, is quite opposite to what has been set as one of the targets in Finland's health program.

The sociodemographic mortality differentials found in Martelin's study were interpreted in the light of various factors affecting mortality at older ages. As the data do not include information on all factors which could be supposed to affect mortality, for example on individual health habits, indirect ways of inference were used. Support was found for several hypotheses concerning the effect of environmental, behavioral, psychological and genetic factors. In particular, several observations about mortality differences appear to agree with the assumption of the deleterious effects of smoking even at advanced ages. This conclusion coincides with several studies based on direct measurement of individual habits. Signs of possible effects of work history, housing conditions, social support, dietary habits and psychological resources to cope with various problems, for example, were detected as well.

Conclusions about the future trends of the mortality of the elderly in Finland were based on evaluating the possibilities of the underprivileged groups to reach the current level of the advantaged ones, and considering the likelihood of a further extension of life expectancy in the latter groups. Summarizing the evidence, it appears likely that the decline in elderly mortality will continue in the future in Finland. There is obviously room for further advances: during the latter half of the 1980s, even highly educated Finns represented a slightly lower life expectancy at the age of 65 years than the current level of the entire population of Japan.

This study has shown that social, economic and demographic attributes associated with mortality among the middle-aged play an important role also at advanced ages. It should be noted, however, that this study aimed at clarifying the trends and differentials in life expectancy, without addressing the question of the quality of life with respect to health and functional ability. In order to make progress in solving the questions concerning the possibilities and consequences of increases in life expectancy, a combined effort involving various types of research on health and mortality is called for.

The study is mainly based on a data set that covers the entire population of Finland during the period 1971-1990, compiled at Statistics Finland by linking death records individually with census records. The empirical results are reported in more detail in five separately published papers. 


\section{Sociodemographic factors and mortality}

In his study on sociodemographic factors and mortality among Finnish women in 1981-1985, Pekka Martikainen who took his doctor's degree in London examines how different measures of socioeconomic status are related to mortality among 35-64 yearold Finnish women and how these relationships differ according to employment status, marital status, motherhood or age. He also assesses the effects of combining marital, parental and work roles on mortality.

Socioeconomic mortality differentials among women exist for all groups of causes of death analyzed in this study. The pattern of mortality differentials was broadly similar according to education, occupational status, disposable family income and housing tenure. However, mortality differentials by disposable family income were very small compared to the other measures of socioeconomic status. Multivariate analyses by education and occupational status indicated very strong mortality differentials according to education for cancer (except breast cancer) and especially circulatory diseases.

Relative socioeconomic mortality differentials were broadly similar in all subgroups defined by parental status, economic activity and marital status, except among single women who had very large educational mortality differentials.

The analysis also shows that socioeconomic mortality differentials within each sex are more or less equally large according to both the person's own and the spouse's education or occupational characteristics for a wide range of causes of death. Moreover, among both women and men cross-classifications between own and spouse's socioeconomic status do not indicate important mortality differentials over and above those already displayed by its two separate parts.

The author states that the results call into question the argument that the mortality of married women should be analyzed on the basis of their husband's socioeconomic characteristics. Furthermore, the advantages of cross-classifying both spouses' socioeconomic characteristics in mortality analyses are very limited.

The »multiple role» hypothesis again suggests that the effects of combining marital, parental and work roles on mortality are harmful, but the »role accumulation» hypothesis argues that the benefits will outweigh the possible harmful effects.

Finnish women with all three roles of wife, mother and employee had low mortality. This, however, was a reflection of the main effects of these three variables. Only single mothers with more than one child - about four percent of the study population - were characterized as having a somewhat deviant mortality from what was to be expected on the basis of the main effects model.

According to the study neither of the hypotheses on multiple roles is very relevant for the analysis of female mortality and more attention should be devoted to understanding the contribution of possible selection effects and the contribution of the »healthy worker effect» in creating low mortality for the employed.

\section{Determinants of disability pension incidence}

In her study »Työkyvyttömyyseläkkeelle siirtymisen yhteiskunnalliset taustatekijät» (Social and societal determinants of disability pension incidence in Finland), Helka Hytti analyzes the changes between 1972 and 1985 in the incidence of disalibity pensions in various population groups and determines which background factors influenced these changes. The target group consisted of occupationally active persons between 40 and 50 years of age. The disability pensions in the system studied are awarded under the National Pension Act and are available to the entire working-age population. 
In the first part, disability pension incidence trends in various demographic and socioeconomic groups are described. The second part is aimed at identifying which background factors related to the health status of the population and social and economic development have influenced changes in disability pension incidence.

The material for the study was obtained by using the personal identity code to crossmatch data from population censuses, official cause of death registers, data of disability, unemployment and farmers' change-of-generation pensions.

The various sectors of industry are lined up roughly according to the commonly acknowledged level of physical strain and presence of health hazards in the work environment. The incidence of disability pension was highest in forestry, mining and construction. While manual workers were the group most susceptible to risk of disability throughout nearly the entire period studied, upper white-collar workers were the group least likely to retire. The changes in the incidence of disability pensions were partly attributable to improvements in the overall health status of the population, but also to employment and social security trends.

The author states that owing to the availability of other early retirement options, disability pensions have not been used as a labor policy instrument to any significant extent. On the other hand, the improvement of the disability pension system has contributed to the revitalization of the labor force by encouraging retirement from the physically most demanding and economically less productive jobs.

An article based on this study and dealing more exhaustively with the incidence of disability pensions in Finland is included in this yearbook.

\section{Mortality during the famine of the $1860 \mathrm{~s}$}

In his thesis »Deprivation and Disease» Kari Pitkänen examines mortality during the last Finnish pre-industrial subsistence crisis of the $1860 \mathrm{~s}$.

The misfortunes began in 1862 when large areas of the country experienced a crop failure. Even though grain prices reached and maintained relatively high levels after the calamity, the demographic consequences remained negligible. Due to subsequent poor harvests and another crop failure in 1865, economic circumstances deteriorated further and a significant portion of the farmers became impoverished. As a consequence, unemployment increased among the landless agricultural workers in the affected regions and the municipal poor-relief organizations were rendered ineffective. The poorer segments of the population began to suffer from significant malnutrition, and signs of famine-induced social chaos became detectable. In addition, mortality levels were elevated in areas which were struck by economic deprivation. In 1867 most regions of the country experienced either a nearly total crop failure or a very poor harvest. During the spring and early summer of 1868 Finland suffered from an intense mortality crisis. During the famine years of 1866-1868, short-term population losses (including a deficit in births) reduced the pre-famine population of 1.8 million individuals by about nine percent.

Due to the relatively late occurrence of the famine and the high quality of Finnish population statistics, it has been possible to examine the calamity in great detail. The demographic data has permitted the delineation of temporal, regional and age-specific changes in mortality. The annual reports of the District Medical Officers contain ample information which, for example, has enabled specification of the diseases which were primarily responsible for excess mortality. By using various report materials, the price series of grain and oral tradition, the progress of economic deprivation and its regional and social differentials have been depicted by the author. 
A comparison of the demographic data and the various supplementary materials confirmed that the temporal, regional and social patterns of the mortality response were closely associated with the degree of economic deprivation and nutritional stress. However, at a general level, this finding does not indicate what kind of causal mechanisms linked economic distress with the mortality outcome.

The author states that usually two competing models have been offered. According to the first explanation the mortality increases were primarily determined by a reciprocal influence (referred to as »synergy») between two factors: malnutrition and infectious disease. The simultaneous presence of these factors resulted in a more serious outcome than one would have expected from their combined effect, had they been working independently. According to the other explanation, a synergistic relationship between malnutrition and infectious disease is questionable. The primary association between economic deprivation and the mortality increases has been in social dislocation, which has been an essential characteristic of famines. Social disarray increased contacts between individuals, resulted in crowding and a deterioration of sanitary conditions. All these factors enhanced the spread of infectious diseases.

As the author concludes, it is apparent that the problem in determining the significance of these competing explanations is the fact that economic deprivation, nutritional stress and social dislocation are closely associated with one another. Examination of the Finnish famine revealed that all these factors progressed hand in hand. Nonetheless, the examination of certain features of the famine of the 1860 s demonstrated that both of the outlined mechanisms were important in determining the mortality outcome. Still, even the use of the unusually detailed Finnish historical materials has not permitted conclusive ascertainment of the relative importance of the synergistic nutritioninfection interactions versus social dislocation as determinants of mortality changes.

The author states that there is an important lesson to be learned from the analysis. In older historical research the synergistic relationship between malnutrition and infectious disease was often taken for granted. In some recent literature, on the other hand, social dislocation has been emphasized as being the principal reason for famine-related mortality increases. However, one should be careful not to go too far to the other extreme. Otherwise, one is in danger of advocating a conclusion which may be as misleading as the older ones, which stressed the sole significance of synergistic nutrition-infection interactions. Besides, as the author stresses, one should realize that synergy and social dislocation cannot be viewed simply as two separable competing sets of variables. Both of them interact in a complex way with environmental and other biological and social factors. Due to such (often »synergistic») relationships, the effects of synergistic nutrition-infection interactions and social dislocation cannot be completely disentangled. In fact, it may be unrealistic to even attempt to establish the primacy of one set of factors over the other.

\section{Family formation in Estonia}

The content of Andres Vikat's thesis »Family Formation in Estonia» is shaped by the data situation and the social system that prevailed in Estonia over the four and a half decades of the Soviet rule. During this period decision-making was not based on information and the authorities expressed no need for demographic data. Hence, up to the second half of the $1980 \mathrm{~s}$, access to age-specific demographic data was restricted, and only very aggregated data were published.

The author hypothesizes that despite the difference in social systems, Estonians' family formation behavior follows the trends universally observed in western and north- 
ern Europe; in contrast, the behavior of Slav immigrants in Estonia is different, being shaped by a different cultural tradition and demographic history.

The aggregate indices of family formation over the Soviet period are analyzed in comparison with corresponding indices of other European countries. Aggregate demographic indicators are computed from published and unpublished tabulations at Statistics Estonia, and from the 1989 census at the Estonian Interuniversity Population Research Centre (EKDK). The differences within Estonia are analyzed using gross nuptiality tables for Estonians and non-Estonians from the two latest censuses (1979 and 1989), and life course data obtained from a Tallinn sample survey from December 1988 (1,584 respondents of both sexes). The author has applied advanced methods of analysis: exponential models and logit models.

A high illegitimacy ratio distinguishes Estonia from Eastern European countries. The ratio is even higher than in most countries of Western Europe and Finland. Only Iceland, Sweden, Denmark and Norway have a higher level. The increase of the illegitimacy ratio was particularly distinct at the end of the $1980 \mathrm{~s}$ and the beginning of the $1990 \mathrm{~s}$. This period is also characterized by a steep decline of the total first marriage rate, such a decline was observed approximately 20 years earlier in Western Europe. As a consequence, the author expects a rise of the mean age of marriage in a few years.

The trends of the total first marriage rate, the mean age at first marriage and the illegitimacy ratio did not coincide with changes typical for the post-1965 period in Western Europe. Still in the second half of the 1980 s, the total first marriage rate and mean age at first marriage were close to those of Eastern Europe. By 1991, however, the total first marriage rate had dropped to the western European levels. Currently, family formation in Estonia follows the Western European trends with a considerable time lag.

Vikat stresses that any demographic research in Estonia cannot overlook the fact that almost 40 percent of the population are immigrants and their descendants represent demographic behavior and family formation different from that of Estonians'. Nuptiality tables also indicate that the first marriage of Estonians occurs later than that of non-Estonians, and that the proportion never-married is higher among Estonians at all ages. The data of the 1979 and 1989 censuses indicate that the difference increased in the eighties.

The study shows that during the whole postwar period there has been a shift toward younger age in starting the first union. The trend toward younger age is almost the same in both ethnic groups. However, Estonians are considerably more likely to enter into a consensual union than non-Estonians. The proportion of couples who have ever participated in a premarital union is not much lower amongst the youngest cohorts of Estonians than in Western European countries.

The decreasing interval between start of union and first birth is another characteristic trend for the whole postwar period. Childbirth basically occurs in marriage and the majority of consensual unions are legalized before first birth. The woman's pregnancy often serves as an incentive to marriage. However, a sharp rise in extra-marital births and a growing proportion of marriages starting after first birth during the last few years indicate that there is a change taking place: the pressure to legalize a nonmarital union before first birth has decreased.

Studying at the university is a significant factor postponing the start of first union especially for females. It also reduces the probability of having a first child during that period. However, there are no signs that highly educated couples are more likely than less educated to remain childless - they just postpone the first birth.

The author presents the housing and contraceptive situation as the most obvious determinants of the family formation processes. During the Soviet period there was 
no housing market: housing was distributed according to bureaucratic rules, family size was one criteria justifying an application for a (new) dwelling. Non-marital couples were officially treated as two single persons, so it was more practical to marry. The lack of a regular supply of modern contraceptives in the former Soviet Union clearly discouraged deliberately childless unmarried unions.

Estonian society is currently going through a considerable change moving from the socialist system to a market economy. Several features that have been regarded in the West as incentives for changing demographic behavior over the last few decades are increasingly manifest in Estonian society. The Estonian society can again progress according to its own norms and expectations without foreign interference. It is therefore likely that Estonian family formation and demographic behavior will follow the development of Northern and Western Europe.

\section{Family and societal development}

Beatrice Moring's thesis »Skärgårdsbor: hushåll, familj och demografi i finländsk kustbygd på 1600-, 1700- och 1800-talen» (Household, family and demography in Finnish coastal regions during the 17 th, 18 th and 19 th centuries) concerns the interaction between household and family and, on the other hand, economic, demographic and social development in the coastal region of southwestern Finland from 1635 to 1920.

At the beginning of the period the region studied was in the same situation as a mountain area. The possibilities for economic expansion were nearly nonexistent. The cultivated area and grassland could not be extended, as there was no suitable land left. Fishing waters were limited by juridical restrictions and technological factors.

The methods used are cross-sectional surveys of household structure and longitudinal studies of demographic data. A data base, compiled from parish records, has been used for the reconstruction of families in one of the parishes between 1738 and 1811 . This gives information on demographic data and social differences of these variables, as well as changes over the time.

The main results of the study are that both mean household size and its structure change over time but the reason for this development is not due to changes in the general behavior of the population, but rather to changes in the social structure of the society. Legal and economic changes facilitate the establishment of non-landowning households. While the landowning population maintains a patrilocal complex household system with intergenerational cohabitation, the landless establish neolocal simple households. The major force behind the overall change in the society is the multiplication of simple proletarian households. The author draws the conclusion from studying this cultural environment with several household strategies that it would be useful to study the interaction between social stratification and different household systems in future family studies.

A great part of the study concerns the demographic circumstances in the area studied.

Demographic development is portrayed with data giving information on age at marriage, number of births, premarital conceptions, birth intervals, age at last birth, infant mortality and its causes, general mortality and causes of death, migration etc. Especially the field of fertility has been analyzed more thoroughly, with attempts to find the reasons behind development, such as methods of family planning, breast-feeding, marital living pattern, etc.

The author is a historian and the thesis is part of a Nordic research project entitled »Coastal Regions in Change 1650-1950». 


\section{The theses}

Hytti, Helka. 1994. Työkyvyttömyyseläkkeelle siirtymisen yhteiskunnalliset taustatekijät. Kansaneläkelaitoksen julkaisuja M:87. Helsinki: Kansaneläkelaitos.

Koskinen, Seppo. 1994. Origins of Regional Differences in Mortality from Ischaemic Heart Disease in Finland. Research reports, 41. Helsinki: NAWH National Research and Development Centre for Welfare and Health. 204 pp.

Martelin, Tuija. 1994. Differential Mortality at Older Ages: Sociodemographic Mortality Differences Among the Finnish Elderly. Publications of the Finnish Demographic Society, 16. Helsinki: The Finnish Demographic Society. 95 pp.

Martikainen, Pekka. 1995. Women's employment, marriage, motherhood and mortality: a test of the multiple role and role accumulation hypotheses. Social Science \& Medicine 40:199-212.

Martikainen, Pekka. 1995. Socioeconomic mortality differentials in men and women according to own and spouse's characteristics in Finland. Sociology in Health and Illness 17:353-375.

Martikainen, Pekka. 1995. Mortality and socioeconomic status among Finnish women. Population Studies 49(1):71-90.

Moring, Beatrice. 1994. Skärgårdsbor: hushåll, familj och demografi i finländsk kustbygd på 1600-, 1700- och 1800-talen. Bidrag till kännedom av Finlands natur och folk, 145. Helsingfors: Finska Vetenskaps-Societeten. $173 \mathrm{pp}$.

Pitkänen, Kari J. 1993. Deprivation and Disease: Mortality During the Great Finnish Famine of the 1860 s. Publications of the Finnish Demographic Society, 14. Helsinki: The Finnish Demographic Society. 176 pp.

Vikat, Andres. 1994. Family Formation in Estonia. Publications of the Finnish Demographic Society, 15. Helsinki: The Finnish Demographic Society. 176 pp. 